\title{
Long-term safety and efficacy of raloxifene in the prevention and treatment of postmenopausal osteoporosis: an update
}

\author{
Enrico M Messalli \\ Cono Scaffa \\ Department of Gynaecology, \\ Obstetrics and Reproductive \\ Medicine, Second University \\ of Naples, Largo Madonna delle \\ Grazie I, Naples, Italy
}

Correspondence: Enrico M Messalli Department of Gynaecology, Obstetrics and Reproductive Medicine, Second University of Naples, Largo Madonna delle Grazie I, 80138 Naples, Italy $\mathrm{Tel} / \mathrm{Fax}+390815665610$

Email enricom.messalli@unina2.it

\begin{abstract}
The integrity of bone tissue and its remodeling that occurs throughout life requires a coordinated activity of osteoblasts and osteoclasts. The decreased estrogen circulating level during postmenopausal transition, with a prevalence of osteoclastic activity over osteoblastic activity, represents the main cause of bone loss and osteoporosis. Osteoporosis is a chronic disease requiring long-term therapy and it is important to evaluate the efficacy and safety of treatments over several years, as the fear of health risks is a common reason for discontinuing therapy. Raloxifene is a selective estrogen receptor modulator (SERM) leading to estrogenagonist effects in some tissues and estrogen-antagonist effects in others. Raloxifene is effective to prevent and treat postmenopausal vertebral osteoporosis, with reduction of spine fractures and, in post-hoc analyses, non-spine fractures in high-risk subjects. Moreover, raloxifene reduces the risk of invasive breast cancer and improves the levels of serum lipoprotein but with an increased risk of venous thromboembolism and fatal stroke, without significant change in the incidence of coronary events. For these reasons the overall risk-benefit profile is favorable. Therefore, when considering the use of raloxifene in a postmenopausal woman, we should take into account the osteoporosis-related individual risk and weigh the potential benefits, skeletal and extra-skeletal, against the health risks.
\end{abstract}

Keywords: raloxifene, osteoporosis, menopause

\section{Introduction}

Osteoporosis is a systemic skeletal disease characterized by low bone mass and microarchitectural deterioration of bone tissue, with a consequent decrease in bone mineral density (BMD) and increase in bone fragility and susceptibility to fracture. ${ }^{1}$

The decreased estrogen circulating level during postmenopausal age represents the main cause of bone loss and osteoporosis ${ }^{2,3}$ and about $54 \%$ of women age 50 years or older will have an osteoporotic fracture during their lifetime. ${ }^{4}$ A rapid decrease of bone mass is evident in the first 5 to 10 years following the menopause and the annual rate of bone loss is at a maximum of about $4 \%$ during the former 4 years, ${ }^{5}$ then declines to $1 \%{ }^{6}$ In this period, the physiological bone remodeling is characterized mainly by a relevant prevalence of the resorption due to osteoclastic activity. ${ }^{7}$

Osteoporosis and osteoporosis-related fractures are a relevant and increasing problem for public health: in the year 2000, there were estimated to be 620,000 new fractures at the hip, 574,000 at the forearm, 250,000 at the proximal humerus and 620,000 clinical spine fractures in men and women aged 50 years or over in Europe. ${ }^{8}$ Osteoporotic fractures also occur at many other sites including the pelvis, ribs, and distal femur and tibia and, collectively, all osteoporotic fractures account for 2.7 million fractures in men and women in Europe at a direct cost of $€ 36$ billion. ${ }^{9}$ Moreover, elderly people represent the fastest growing age group and with an aging population the incidence of 
hip fractures is likely to rise substantially: it is predicted that the estimated number of hip fractures worldwide will rise from 1.7 million in 1990 to 6.3 million in $2050 .^{10}$

The increasing prevalence and cost of osteoporosis have heightened interest in the efficacy and safety of agents available to treat the bone loss associated with osteoporosis. During the last 20 years, many drugs have been granted a marketing license for treatment of osteoporosis. Bisphosphonates are the most widely prescribed drugs: alendronate and risedronate are given daily or weekly and have demonstrated efficacy on reduction of fracture rates at the spine and hip; ibandronate has demonstrated spine antifracture efficacy with intervals between doses greater than weekly. Strontium ranelate is suggested to be the first medication to uncouple bone formation from bone resorption and it has shown antifracture efficacy at all sites in a large number of postmenopausal women. The selective estrogen-receptor modulator (SERM) raloxifene reduces spine fractures and non-spine fractures in high-risk subjects in post-hoc analyses with extra-skeletal benefits (such as in the breast). ${ }^{11}$

Osteoporosis is a chronic disease requiring long-term therapy; thus it is important to evaluate the efficacy and safety of therapies over several years. In fact, despite treatment options that can reduce the risk of fracture in patients with osteoporosis, few patients fully adhere to current therapies and the fear of health risks is a commonly cited reason for discontinuing therapy: a recent study reported 1-year adherence rates of less than $25 \%$ for all osteoporosis therapies examined. $^{12}$

The aim of this review is to analyze the long term safety and efficacy of the second-generation SERM raloxifene, the only drug approved worldwide for the prevention and treatment of postmenopausal osteoporosis. In particular, raloxifene $60 \mathrm{mg} /$ day oral dosage was approved by the US Food and Drug Administration (FDA) for postmenopausal osteoporosis prevention in 1997 and postmenopausal osteoporosis treatment in 1999; until 2006 over 50,000 women have participated in clinical trials with this drug and over 40 million prescriptions for raloxifene have been written worldwide. ${ }^{13}$ In a search of Medline (www.pubmed.gov) through December 2008 for "raloxifene" we found 2322 items (1889 items on humanonly studies).

\section{Mechanism of action}

The integrity of the skeleton and the bone remodeling that occurs throughout life requires the coordinated regulation and activity of osteoblasts and osteoclasts. The number of active osteoclasts is determined by the net result of differentiation and fusion of osteoclast precursors and by the loss of osteoclasts through apoptosis. An increase in active osteoclast pool size, with increased bone resorption and decreased bone mass, occurs in many osteopathic disorders, including postmenopausal osteoporosis.

Estrogens act on bone with two activities: ${ }^{14}$ one directly mediated by the estrogen receptors (ER) present on the bone cell, ${ }^{15}$ the other, indirect and delayed, that acts through a change of calcium metabolism at the level of the intestine, kidneys and parathyroids. ${ }^{16}$ Estrogen deficiency determines an inhibition of mature osteoblasts and osteocytes, while it promotes faster osteoblastic apoptosis. ${ }^{17}$

In the last few years, many studies have been published focusing the attention of the media on possible side effects of hormone replacement therapy on the breast and the cardiovascular system. ${ }^{18-20}$ Consequently, more data have been provided in patients with osteoporosis by the use of SERMs, of which raloxifene was the first to be validated in the reduction of vertebral fractures in osteoporotic menopausal women..$^{21,22}$

Unlike estrogens, which are pure agonists, and anti-estrogens, which are pure or selective antagonists, raloxifene exerts selective agonist or antagonist effects on various estrogen target tissues.

The mechanisms of the tissue-selective, mixed agonistantagonist action of SERMs, although still only partly understood, are gradually becoming clearer. ${ }^{23}$ Most of the pharmacology of SERMs can be explained by three interactive mechanisms: differential ER expression in a given target tissue, differential ER conformation on ligand binding, and differential expression and binding to the ER of coregulator proteins. ${ }^{24}$

In particular, raloxifene binds to the ER, leading to estrogen-agonist effects in some targets (bone and lipid metabolism) and estrogen-antagonist effects in others (breast and endometrium). ${ }^{25}$ Raloxifene has anti-estrogenic effects in the breast, competitively blocking estrogen-induced DNA transcription ${ }^{26}$ and inhibiting the growth of estrogenstimulated mammary cancers in animals. ${ }^{27}$

Raloxifene plays an analogous role to estrogens on bone tissue, but its osteoblastic actions remain to be fully clarified. In in vitro studies raloxifene modulates the bone homeostasis inhibiting osteoclastogenesis and the bone resorption with dose-dependent activity. ${ }^{28}$ This is a complex mechanism that implies direct and indirect activities on bone cells $\mathrm{s}^{16,28}$ and a down-regulation of the osteoblastic production of IL-6 and other cytokines. ${ }^{28-30}$

New hypotheses on management of osteoporosis have arisen from the recent discovery of a cytokine pathway that 
regulates osteoclastogenesis and modulates osteoclastic bone resorption: the OPG/RANK/RANKL system. ${ }^{31,32}$ Osteoprotegerin (OPG) is a protein expressed by osteoblasts that, linking the receptor activator of nuclear factor $\kappa \mathrm{B}$ (RANK) ligand (RANKL), blocks the process of osteoclastic differentiation and modulates osteoclastic apoptosis. ${ }^{32-34}$ The binding of RANKL to RANK on osteoclasts initiates a cascade of intracellular signaling events ${ }^{35}$ and OPG, acting as a decoy receptor for RANKL, blocks the process of osteoclast differentiation and modulates apoptosis. ${ }^{29,36}$ OPG is a negative regulator of osteoclast mediated bone resorption $^{37}$ and when RANKL overwhelms OPG, bone resorption can become excessive leading to osteoporosis; therefore, a healthy skeleton could depend on a balanced RANKL/OPG ratio. ${ }^{38}$ Raloxifene stimulates the production of OPG from osteoblasts, as demonstrated in vitro ${ }^{28,29,39}$ and in vivo, ${ }^{30}$ carrying out their antiresorption activity, at least in part, as a means of the OPG/RANK/RANKL system, and it could improve osteoporosis, also through an increase of OPG production by osteoblasts.

Therefore, raloxifene was associated with a statistically highly significant suppression of bone resorption markers osteocalcin (-26.3\%) and urinary cross-linked N-telopeptides of type I collagen (NTX) $(-34 \%),{ }^{40}$ and both newly synthesized $(\alpha \alpha \mathrm{CTX})$ and mature $(\beta \beta \mathrm{CTX})$ collagen type I degradation. ${ }^{41}$

\section{Efficacy}

In the first "over 1000 participants" raloxifene trial, in 1145 healthy postmenopausal women aged 45 through 60 years the lumbar spine BMD increased from baseline to 36 months by $1.28 \pm 0.23 \%$. Comparable BMD changes were observed in the hip and total body. ${ }^{42}$

By clinical trials on efficacy of raloxifene, the Multiple Outcomes Raloxifene Evaluation (MORE) study was designed to test whether raloxifene reduced the risk for fracture in postmenopausal women with osteoporosis. From 1994 to 1998,7705 postmenopausal women with osteoporosis (mean age 66.5 ) were randomized to receive $60 \mathrm{mg}$ raloxifene, 120 mg raloxifene, or placebo (mainly in the United States and Europe). At 36 months of follow-up, the risk for vertebral fracture was reduced $30 \%$ in women with a vertebral fracture and $55 \%$ in women without prevalent fractures over 3 years. Moreover, the BMD gains after 3 years were $2.1 \%$ in the spine and $2.6 \%$ in the femur, while BMD gains after 4 years were $2.6 \%$ in the spine and $2.1 \%$ in the femur with a $50 \%$ reduction in the fourth year versus a $55 \%$ reduction in years 0 to 3 (BMD increases were significant during the third year, but not during the fourth year). ${ }^{40,43}$ In this trial, raloxifene not only shows benefits in the absolute reduction of the risk of vertebral fractures, but also ameliorates the severity of future vertebral fracture ${ }^{21}$ and can decrease the absolute number of vertebral fractures. ${ }^{44}$ Moreover, raloxifene showed a fast-acting efficacy on reduction of vertebral fracture $(-68 \%, \mathrm{p}=0.01$, in a 1 -year post hoc analysis; $-90 \%, \mathrm{p}=$ 0.01 , in a 6 -month post hoc analysis; $-80 \%, \mathrm{p}=0.034$, in a 3-month post hoc analysis). ${ }^{45,46}$

The Continuing Outcomes Relevant to Evista (CORE) trial examined the effect of an additional 4 years of raloxifene therapy on the incidence of invasive breast cancer (primary endpoint) in women in the MORE trial who agreed to continue therapy (4011 women with a mean age of 65.8). In this population BMD was higher in the raloxifene group than in the placebo group, by $2.2 \%$ in the spine and $3 \%$ in the total hip $(\mathrm{p}<0.01){ }^{47}$

Also the Raloxifene Use for The Heart (RUTH) trial, that evaluated as primary endpoint the effect of raloxifene on cardiovascular events in 10,101 postmenopausal women for a median of 5.6 years (mean age 67.5 years), clearly demonstrates the benefits of raloxifene in older women in the prevention of clinical vertebral fracture $(-35 \%, p=0.007)$, but not for nonvertebral fractures ( $\mathrm{p}>0.05$ versus placebo), irrespective of presence or absence of risk factors for fracture. ${ }^{48,49}$

The Evista Versus Alendronate (EVA) trial is the first head-to-head trial with fracture as a primary endpoint; it is a multicenter, double-blind, double-dummy, randomized trial with two active treatment arms. This trial compares directly the osteoporotic fracture risk reduction efficacy of raloxifene and alendronate in 1412 postmenopausal women with osteoporosis (mean age of 66 years). The EVA trial showed that raloxifene decreases the incidence of osteoporosis-associated fractures. ${ }^{50}$ Although women treated with alendronate showed a greater BMD increase compared with raloxifene use, no statistical difference in the fracture risks between alendronate and raloxifene was found. Lumbar spine, femoral neck, and total hip BMD were increased from baseline at 2 years in each group $(p<0.001)$ suggesting that both drugs serve equally as effectively, if our purpose was only the prevention of fracture. ${ }^{51}$ In addition, superiority in the prevention of fractures has not been shown for any bisphosphonate class agent and superiority for the prevention of vertebral fractures has not been demonstrated for bisphosphonates compared with calcitonin, calcium, or raloxifene. ${ }^{52}$ On the contrary, a recent study showed an efficacy of alendronate greater than raloxifene in increasing lumbar BMD and a marked 
reduction of bone turnover compared with raloxifene in elderly women with osteoporosis..$^{53}$

In the prevention trials, fewer women in the raloxifene treatment group progressed from normal to osteopenia and from osteopenia to osteoporosis. In fact, 5 years of raloxifene treatment in healthy postmenopausal women preserved BMD and significantly reduces the likelihood of development of osteoporosis. ${ }^{54}$ On the contrary, raloxifene discontinuation after 5 years was followed by significant declines in BMD at the lumbar spine and femur $(-2.4 \%)$ within the first year. ${ }^{55}$ However, no data are available on the fracture risk after raloxifene discontinuation. ${ }^{56}$

The risk reduction for non-vertebral fractures in the overall MORE population was not significant, but a reduction of $47 \%(p=0.04)$ was noted in a post hoc analysis of patients with severe prevalent vertebral fractures. ${ }^{44}$ However, even if raloxifene does not influence periosteal apposition in the proximal femur, it produces small but significant improvement in resistance to axial and bending stresses. $^{57}$

In the CORE trial, the risk of at least one new non-vertebral fracture was similar in the placebo $(22.9 \%)$ and raloxifene (22.8\%) groups (hazard ratio [HR] 1.0). ${ }^{47}$ The incidence of at least one new non-vertebral fracture at six major sites (clavicle, humerus, wrist, pelvis, hip, and lower leg) was $17.5 \%$ in both groups. Post hoc Poisson analyses, which account for multiple events, showed no overall effect on non-vertebral fracture risk; however, a decreased risk $(-22 \%)$ was found at six major non-vertebral sites in women with prevalent vertebral fractures (HR $0.78, \mathrm{p}=0.017$ ) and with severe vertebral fractures (HR 0.64, p < 0.05). ${ }^{47}$ The RUTH trial also showed that raloxifene was not sufficient for preventing non-vertebral fractures, because there was no difference in non-vertebral fractures between the raloxifene treatment and placebo groups. ${ }^{48,49}$ One explanation for this apparent absence of a non-vertebral effect is that the weaker antiresorptive effects of raloxifene can return high bone turnover to normal and prevent micro-architectural deterioration in trabecular bone, but the reduction of fracture risk at sites of cortical bone, such as the hip, requires more potent antiresorptive effects. ${ }^{23}$

In a study on 1051 non-vertebral fractures observed within 12 months, no large differences in fracture risk were found between risedronate (HR 1.01) or raloxifene (HR 1.18 ) and alendronate. However, among those with a fracture history, raloxifene recipients experienced more non-vertebral fractures within 12 months (HR 1.78) compared with alendronate recipients. ${ }^{58}$
Recently a 3-year open-label comparative study on 90 postmenopausal women has shown that raloxifene plus ossein-hydroxyapatite compound appears to be more effective in controlling bone loss than raloxifene plus calcium carbonate for the control of bone loss in postmenopausal women. ${ }^{59}$

\section{Safety}

\section{Endometrium}

Raloxifene differs from tamoxifen, a first-generation SERM, principally by its lack of stimulation of the endometrium. ${ }^{60}$ No increase in the risk for endometrial cancer was observed in the CORE trial: there was no difference in the incidence of uterine cancer, endometrial hyperplasia, or postmenopausal bleeding between the raloxifene and placebo treatment groups $(\mathrm{p}>0.5)^{47,61,62}$

In the Study of Tamoxifen and Raloxifene (STAR), a 1999-2004 prospective, double-blinded, randomized clinical trial on 19,747 postmenopausal women (mean age 58.5 years), raloxifene did not show the same effect on the uterus as tamoxifen (endometrial cancer relative risk [RR] 0.62 , endometrial hyperplasia RR 0.16)..$^{63,64}$

In another study, 5 years' raloxifene treatment in healthy postmenopausal women was not associated with an increased rate of vaginal bleeding, endometrial hyperplasia, or endometrial carcinoma, compared with placebo: similar incidence of vaginal bleeding $(p=0.999)$ or of mean endometrial thickness of more than $5 \mathrm{~mm}$ at baseline and at each visit, up to the 5 -year endpoint ( $p \geq 0.349$ ); no diagnoses of endometrial hyperplasia or endometrial cancer were made. $^{54}$

\section{Breast}

Raloxifene has anti-estrogenic effects in the breast, competitively blocking estrogen-induced DNA transcription ${ }^{27}$ and inhibiting the growth of estrogen-stimulated mammary cancers in animals. ${ }^{27}$ Moreover, raloxifene reduces mammographic breast density ${ }^{64}$ and breast cancer proliferative indices $^{66}$ and plays a protective role in decreasing the incidence of breast cancer.

The MORE trial showed a breast cancers risk reduction of $65 \%$ (RR 0.35) and 76\% (RR 0.24) among the patients with invasive cancer. The risk reduction was limited to ER-positive tumors (RR 0.10), with no decrease occurring in ER-negative tumors (RR 0.88). ${ }^{67}$ Continued follow-up of MORE participants showed an ongoing breast cancer risk reduction in postmenopausal women treated with raloxifene: the risk reduction was $72 \%$ (RR 0.28 ) and $84 \%$ (RR 0.16 ) of the ER-positive breast cancers. ${ }^{68}$ 
In the CORE trial that examined the effect of an additional 4 years of raloxifene therapy in women in the MORE trial who agreed to continue therapy, the primary endpoint was the incidence of invasive breast cancer; a secondary objective looked at the incidence of ER-positive invasive breast cancers: the risk for invasive breast cancer was reduced by $59 \%$ (HR 0.41) in the raloxifene group compared with the placebo group, and the incidence of ER-positive invasive breast cancer by $66 \%$ (HR 0.34 ). However, for the prevention of either invasive ER-negative breast cancer or non-invasive breast cancer, the effect of raloxifene seemed to be uncertain, since no statistical difference was noted between the treatment group and the placebo group (HR 1.13, p $=0.86$ and HR $1.78, \mathrm{p}=0.47$ respectively). Collectively, during the 8 years of the MORE and CORE trials, a $66 \%$ reduction in the incidence of invasive breast cancer with raloxifene versus a placebo was noted (HR 0.34, p < 0.001) ${ }^{61,62}$ In addition, in a post hoc analysis of postmenopausal women participating in MORE and CORE, raloxifene treatment reduced the risk of invasive and invasive ER-positive breast cancers in women with low bone mass and those with osteoporosis. ${ }^{69}$

The STAR trial on 19,747 postmenopausal women at least 35 years old and with increased risk for developing breast cancer (mean age 58.5 years), indicated with that raloxifene is as effective as tamoxifen in reducing the risk of invasive breast cancer among women at increased risk. In this trial, at $60 \mathrm{mg} /$ day versus tamoxifen $20 \mathrm{mg} /$ day over 5 years, raloxifene was found to be as effective as tamoxifen in postmenopausal Caucasian women at increased risk for invasive breast cancer (RR 1.02), and, although it does not reduce the risk for noninvasive breast cancer like tamoxifen (RR 1.40), it has fewer risks of uterine cancers and venous thromboembolic events. ${ }^{63,64}$

Also the RUTH trial evaluated the effect of raloxifene on invasive breast cancer risk in 10,101 postmenopausal women (mean age, 67.5 years) for a median of 5.6 years: as compared with placebo, raloxifene reduced the risk of invasive breast cancer by $44 \%$ (HR $0.56, p=0.003)$; the benefit was primarily due to a reduced risk of ER-positive invasive breast cancers by $55 \%$ (HR 0.45 ). No significant difference was seen in ERnegative invasive breast cancers between the groups. ${ }^{48,70}$

\section{Heart}

The MORE trial showed no significant overall effect of raloxifene on cardiovascular events but suggested a reduced risk among women who were at increased risk for cardiovascular events. ${ }^{71}$ Also in the CORE trial, there was no difference in the incidence of myocardial infarction. ${ }^{62}$
The RUTH trial evaluated for a median of 5.6 years the effect of raloxifene on cardiovascular events in postmenopausal women with coronary heart disease, peripheral arterial disease, or multiple risk factors for coronary heart disease (mean age, 67.5 years). The outcome was coronary events (ie, death from coronary causes, myocardial infarction, or hospitalization for an acute coronary syndrome), and compared with placebo, raloxifene had no significant effect on the risk of primary coronary events (HR 0.95). ${ }^{48}$

On the contrary, raloxifene therapy has been associated with improvement in the levels of serum lipoprotein cholesterol, ${ }^{60}$ fibrinogen $^{72}$ and homocysteine. ${ }^{73}$ During a 3-year experience, raloxifene significantly reduced total cholesterol $(-5.5 \%, \mathrm{p}<0.001)$ and low-density lipoprotein cholesterol $(-8.7 \%, \mathrm{p}<0.001)$ compared with placebo. No significant changes in high-density lipoprotein cholesterol ( $p=0.257)$ or triglycerides $(p=0.620)$ were detected, ${ }^{54}$ while in a subgroup of women with high triglycerides raloxifene treatment gave an equal or more robust reduction in lipid and lipoprotein parameters. ${ }^{74}$ In addition, raloxifene may improve platelet metabolism in healthy postmenopausal women through an increase in the bioavailability of platelet $\mathrm{NO}$ and the beneficial effects on lipid metabolism. ${ }^{75}$

The favorable effect of raloxifene on markers of cardiovascular risk was coupled with evidence from observational studies that treatment with estrogen was associated with a reduced risk of coronary heart disease in postmenopausal women. ${ }^{76,77}$ In fact, also in large trials, there was no difference in the incidence of myocardial infarction and ischemic heart disease events between the raloxifene and placebo or tamoxifen treatment groups $(\mathrm{p}>0.5) .{ }^{62-64}$ Moreover, raloxifene slowed down the progression of intimamedia thickness in postmenopausal women. ${ }^{78}$

\section{Venous system}

Many studies found that raloxifene use was associated with an increased risk of venous thromboembolic events. ${ }^{20,79,80}$

In the MORE and CORE trials the women had an increased risk for venous thromboembolic events, both deep vein thrombosis and pulmonary embolus, compared with those assigned to placebo (RR 3.1 and 2.17 respectively). ${ }^{40,43,61}$ The risk of venous thromboembolism plus pulmonary embolism due to raloxifene therapy falls within the same range of risk due to estrogen-progestin therapy. The magnitude is similar. ${ }^{68}$ In the RUTH trial, raloxifene was associated with an increased risk of fatal stroke (HR 1.49) and venous thromboembolism (HR 1.44). ${ }^{48}$ In the STAR trial, the risk for venous thromboembolic events (pulmonary emboli and deep vein thromboses) 
is less with raloxifene versus tamoxifen, and the numbers of strokes and transient ischemic attacks that occurred in both groups were statistically equivalent. ${ }^{63,64}$

A recent meta-analysis to evaluate the effect of raloxifene on the risk of deep vein thrombosis and pulmonary embolism showed that therapy with raloxifene was associated with a $62 \%$ increase in the odds (odds ratio 1.62, $\mathrm{p}<0.001$ ), ${ }^{81}$ although raloxifene is probably not associated with an increased risk of arterial thromboembolism. ${ }^{82}$

\section{Others}

Hot flushes, leg cramps, and peripheral edema are all known to be associated with raloxifene use, but the only significant adverse effect of therapy was hot flashes (25\% versus $18 \%$ in the placebo group); hot flashes were typically reported as mild and were not associated with study withdrawal (1.7\% versus $2.4 \%$ for placebo). ${ }^{42}$ In the MORE and CORE experience, the higher frequency versus placebo of hot flashes (12.5\% versus $6.9 \%$ ), cramps of the lower limbs (14.9\% versus $11.8 \%$ ), and fluid retention may be a reason for halting raloxifene use in menopausal women. ${ }^{43,61}$

Raloxifene did not increase the risk of all non-breast cancers, including endometrial cancer. The higher incidence of reported gallbladder disease was not confirmed. ${ }^{79}$ The incidence of cataracts in the raloxifene group is similar to that seen for the general population. ${ }^{63,64}$ The prevalence of low BMD and osteoporosis increases with greater severity of chronic kidney disease, and raloxifene is safe and effective for postmenopausal women affected by chronic kidney disease. ${ }^{83}$

\section{New perspectives}

New third-generation SERMs are expected to demonstrate anti-fracture efficacy at the hip level, with extra-skeletal benefits, but without adverse effects associated with current therapies. Third-generation investigational SERMs include idoxifene, droloxifene, ospemifene, ${ }^{84}$ arzoxifene, acolbifene, levormeloxifene, lasofoxifene, and bazedoxifene. ${ }^{85}$

In particular, lasofoxifene selectively binds to ER with high affinity and it has a half-inhibition concentration similar to that seen with estradiol and thus at least 10-fold higher than those reported for raloxifene and tamoxifen. Moreover, due to increased resistance to intestinal wall glucuronidation, lasofoxifene has a markedly improved oral bioavailability with respect to other SERMs. In preclinical and short-term clinical studies lasofoxifene has shown a proven efficacy in preventing bone loss and lowering cholesterol levels. Dose modeling from phase II studies allowed the selection of lasofoxifene $0.25 \mathrm{mg} /$ day as the lowest fully effective dose. ${ }^{86}$
The phase III program includes two completed identical, placebo-controlled, 2-year studies (Osteoporosis Prevention and Lipid Lowering [OPAL]), an ongoing fracture trial (PEARL) and a comparative trial with raloxifene (CORAL). ${ }^{87}$ The aim is to find a compound with the ideal profile, that is, the alleviation of climacteric symptoms and the prevention of osteoporotic fractures, but without any adverse effects on the breast and endometrium, and no negative effects or even beneficial effects on the cardiovascular system and the brain. ${ }^{88,89}$ In a 2-year phase III study, bazedoxifene prevented bone loss, reduced bone turnover, and was well tolerated in early postmenopausal women with normal or low BMD. ${ }^{90}$

Moreover, combination therapy of old and new-generation SERMs with different drugs may be another area of potential development. For example, a recent small population trial has shown significant benefits for climacteric symptom control with the addition of low-dose esterified conjugated estrogens to standard doses of raloxifene. ${ }^{91}$ The ability of future SERMs to exert estrogenic agonistic/antagonistic activity in a tissue-specific manner may allow these agents to improve bone health while protecting uterine and breast tissue. The combination of a SERM and low-dose estrogen could protect bone, alleviate menopausal symptoms, and improve lipid profile without stimulating proliferation of uterine and breast tissue, which could represent a viable alternative for the treatment of younger menopausal women. Controlled clinical trial data will be needed to confirm these effects. ${ }^{92}$

\section{Compliance to therapy}

Adherence to osteoporosis medications is relatively poor: approximately $20 \%$ to $30 \%$ of patients taking daily or weekly treatments may suspend their treatment within 6 to 12 months of initiating therapy. The majority of patients who discontinue therapy appear to do so because of druginduced adverse effects and fear of health risks, ${ }^{93}$ although withdrawals due to any reason (37\%) and withdrawals due to adverse events (14\%) were not different versus placebo. ${ }^{42}$ In addition, Asian women showed a greater propensity to remain on raloxifene, compared with bisphosphonates, and the women on raloxifene exhibited lower discontinuation rates and higher treatment satisfaction, which addressed the more favorable compliance and tolerance with raloxifene than with bisphosphonates. ${ }^{94}$ Postmenopausal women with osteoporosis, who have poor compliance when taking alendronate, can be switched to raloxifene, because they can still see benefits in BMD and bone turnover with raloxifene after discontinuing alendronate therapy. ${ }^{95}$ 
Table I "Over 1000 participants" trials with raloxifene $(60 \mathrm{mg} /$ day $)$

\begin{tabular}{|c|c|c|c|c|}
\hline Trial & Population & Duration & Efficacy & Safety \\
\hline Johnston et $\mathrm{al}^{42}$ & $\mathrm{I}, 145$ & 3 years & $\begin{array}{l}\text { Spine, hip and total body BMD } \\
\text { preservation in healthy women }\end{array}$ & Tolerability profile comparable to placebo \\
\hline MORE ${ }^{43,44}$ & 7,705 & 4 years & $\begin{array}{l}\text { Cumulative risk of new vertebral } \\
\text { fractures, absolute number and } \\
\text { severity, reduction in osteoporotic } \\
\text { women. No effect on non-vertebral } \\
\text { fracture risk (reduction in post } \\
\text { hoc analysis of patients with severe } \\
\text { prevalent vertebral fractures) }\end{array}$ & $\begin{array}{l}\text { Venous thromboembolism risk increase. } \\
\text { ER+ invasive breast cancer risk } \\
\text { reduction. No effect on cardiovascular } \\
\text { events, stroke, endometrial cancer and } \\
\text { hyperplasia }\end{array}$ \\
\hline $\mathrm{CORE}^{47,60}$ & 4,011 & 4 years & $\begin{array}{l}\text { Lumbar spine and femoral neck } \\
\text { BMD increase in MORE population. } \\
\text { No effect on non-vertebral fracture } \\
\text { risk (reduction in post hoc analysis } \\
\text { of patients with severe prevalent } \\
\text { vertebral fractures) }\end{array}$ & $\begin{array}{l}\text { Venous thromboembolism risk increase. } \\
\text { ER+ invasive breast cancer risk } \\
\text { reduction. No effect on cardiovascular } \\
\text { events, stroke, endometrial cancer and } \\
\text { hyperplasia }\end{array}$ \\
\hline $\mathrm{RUTH}^{48}$ & 10,101 & 5.6 years & $\begin{array}{l}\text { Clinical vertebral fracture } \\
\text { risk reduction in older women } \\
\text { with or at increased risk for coronary } \\
\text { heart disease. No effect on } \\
\text { non-vertebral fracture risk }\end{array}$ & $\begin{array}{l}\text { Venous thromboembolism risk and fatal } \\
\text { stroke increase. ER+ invasive breast } \\
\text { cancer risk reduction. No effect on } \\
\text { coronary heart disease }\end{array}$ \\
\hline $\operatorname{STAR}^{62,63}$ & 19,747 & 5 years & $\begin{array}{l}\text { No statistical different rates of } \\
\text { fracture in raloxifene and tamoxifen } \\
\text { arms in women at increased risk for } \\
\text { invasive breast cancer }\end{array}$ & $\begin{array}{l}\text { Raloxifene as effective as tamoxifen in } \\
\text { ER+ invasive breast cancer risk reduction. } \\
\text { Less venous thromboembolism and } \\
\text { uterine cancer risk for raloxifene versus } \\
\text { tamoxifen. No difference in strokes and } \\
\text { cardiovascular events in raloxifen and } \\
\text { tamoxifen arms }\end{array}$ \\
\hline EVA $^{50,51}$ & 1,412 & I.5 years & $\begin{array}{l}\text { No statistical difference in fracture } \\
\text { risk in raloxifene and alendronate } \\
\text { arms (greater BMD increase with } \\
\text { alendronate) }\end{array}$ & $\begin{array}{l}\text { Venous thromboembolism risk } \\
\text { increase with raloxifene versus } \\
\text { gastrointestinal problems risk increase } \\
\text { with alendronate }\end{array}$ \\
\hline CORAL $^{99}$ & ।,497 & 1.5 years & High compliance & $\begin{array}{l}\text { No significant discontinuation of therapy } \\
\text { for adverse events }\end{array}$ \\
\hline
\end{tabular}

Abbreviations: MORE, Multiple Outcomes Raloxifene Evaluation; CORE, Continuing Outcomes Relevant to Evista; RUTH, Raloxifene Use for The Heart; STAR, Study of TAmoxifen and Raloxifene; EVA, EVista Alendronate comparison; CORAL, COmpliance with RALoxifene therapy.

Moreover, the CORAL multicenter study showed very good patient compliance with raloxifene for treatment satisfaction, health condition, and quality of life; premature discontinuation of therapy was observed in a very low number of women. ${ }^{96}$

\section{Summary and conclusion}

Raloxifene is effective to prevent and treat postmenopausal vertebral osteoporosis, with reduction of spine fractures and, in post-hoc analyses, non-spine fractures in high-risk subjects. This efficacy is confirmed by evidence that raloxifene shows a low number needed to treat (ie, the number of patients to be treated to avoid one radiological vertebral fracture over the duration of the study): range 28 to 31 versus 15 to 64 for alendronate and 8 to 26 for risedronate. ${ }^{97}$
A global index of clinical outcomes, defined as described for the Women's Health Initiative (WHI) trial (the earliest occurrence of coronary heart disease, stroke, pulmonary embolism, invasive breast cancer, endometrial cancer, colorectal cancer, hip fracture, or death because of other causes) was applied to the MORE trial data. ${ }^{19}$ The significant $25 \%$ reduction in global index (150 fewer events per 10,000 women taking raloxifene for an average of 3.4 years) is compatible with a favorable risk-benefit safety profile when raloxifene is used for osteoporosis treatment in postmenopausal women. ${ }^{98}$ Moreover, raloxifene reduces the risk of breast cancer and improves the levels of serum lipoprotein, with a favorable risk-benefit profile against an increased risk of venous thromboembolism and fatal stroke, but without significant change in the incidence of coronary events. 
On the basis of evidence of MORE, CORE, RUTH, and STAR trials, in September 2007, the FDA approved raloxifene hydrochloride tablets for reduction in the risk of invasive breast cancer in postmenopausal women with osteoporosis and in postmenopausal women at high risk for invasive breast cancer. The reduction in incidence of breast cancer was primarily due to a reduction in the incidence of ER-positive invasive breast cancers. There was no reduction in ER-negative invasive breast cancers, and there was no difference in incidence of non-invasive breast cancers between the raloxifene and placebo groups.

Raloxifene is associated with an increased risk of deep vein thrombosis, pulmonary embolism, and retinal vein thrombosis. An increased risk of death due to stroke was observed in a trial in postmenopausal women with documented coronary heart disease or at increased risk for major coronary events. Each individual postmenopausal woman's risk/benefit ratio must be carefully considered. Women should be aware that raloxifene does not completely prevent breast cancer and that regular mammograms and breast examinations are essential. ${ }^{99}$

However, some points of criticism derive from limitations in determining skeletal endpoints in many trials. In fact, the measurement of BMD depends on several parameters and if the variations also in the same patient are not fully comparable, then BMD decrease does not always indicate treatment failure. Moreover, the degree of adherence to therapy, close follow-up and no identifiable secondary cause of osteoporosis are all parameters difficult to evaluate in large randomized controlled trials, even if well conducted.

With an understanding of the risk-benefit ratio and head-to-head comparisons of different drugs, it may be easier to prescribe an appropriate drug in postmenopausal women with osteoporosis, and data from ongoing trials will enhance our understanding of the risks and benefits of raloxifene across multiple diseases that can affect the health of postmenopausal women. ${ }^{100}$

The evidence derived from the literature (Table 1) suggests that the overall risk-benefit ratio of raloxifene is favorable, and the drug is approved widely for the prevention and treatment of postmenopausal osteoporosis..$^{42,98,101}$ In particular, raloxifene, an example of a multifunctional drug, ${ }^{102}$ offers the best benefits for a specific population climacteric symptom-free postmenopausal women who need osteoporosis therapy, fracture and breast cancer prevention, but at a low risk of venous thromboembolism. ${ }^{100}$

\section{Disclosures}

The authors disclose no conflicts of interest.

\section{References}

1. Consensus development conference: diagnosis, prophylaxis, and treatment of osteoporosis. Am J Med. 1993;94:646-650.

2. NIH Consensus Development Panel on Osteoporosis Prevention, Diagnosis, and Therapy. Osteoporosis prevention, diagnosis, and therapy. JAMA. 2001;285,785-795.

3. Luisetto G, Zangari M, Tizian L, et al. Influence of aging and menopause in determining vertebral and distal forearm bone loss in adult healthy women. Bone Miner. 1993;22:9-25.

4. Chrischilles EA, Butler CD, Davis CS, Wallace RB. A model of lifetime osteoporosis impact. Arch Intern Med. 1991;151:2026-2032.

5. Wark, JD. Osteoporosis: pathogenesis, diagnosis, prevention and management. Baillieres Clin Endocrinol Metab. 1993;7:151-181.

6. Hui SL, Wiske PS, Norton JA, Johnston CC Jr. A prospective study of change in bone mass with age in postmenopausal women. J Chronic Dis. 1982;35:715-725.

7. Riggs, BL, Khosla, S, Melton III LJ. A unitary model for involutional osteoporosis: estrogen deficiency causes both type I and type II osteoporosis in postmenopausal women and contributes to bone loss in aging men. J Bone Miner Res. 1998;13:763-773.

8. Johnell O, Kanis JA. An estimate of the worldwide prevalence and disability associated with osteoporotic fractures. Osteoporos Int. 2006;17:1726-1733.

9. Kanis JA, Johnell O; on behalf of the Committee of Scientific Advisors of the International Osteoporosis Foundation. Requirements for DXA for the management of osteoporosis in Europe. Osteoporos Int. 2005; $16: 220-238$

10. Sambrook P, Cooper C. Osteoporosis. Lancet. 2006;367:2010-2018.

11. Close P, Neuprez A, Reginster JY. Developments in the pharmacotherapeutic management of osteoporosis. Expert Opin Pharmacother. 2006; 7:1603-1615.

12. McCombs JS, Thiebaud P, McLaughlin-Miley C, Shi J. Compliance with drug therapies for the treatment and prevention of osteoporosis. Maturitas. 2004;48:271-287.

13. Deal CL, Draper MW. Raloxifene: a selective estrogen-receptor modulator for postmenopausal osteoporosis - a clinical update on efficacy and safety. Women's Health. 2006;2:199-210.

14. Riggs BL, Khosla S, Atkinson EJ, Dunstan CR, Melton III LJ. Evidence that type I osteoporosis results from enhanced responsiveness of bone to estrogen deficiency. Osteoporos Int. 2003;14:728-733.

15. Bord S, Ireland DC, Beavan SR, Compston JE. The effects of estrogen on osteoprotegerin, RANKL, and estrogen receptor expression in human osteoblasts. Bone. 2003;32:136-141.

16. Oleksik AM, Duong T, Pliester N, Asma G, Popp-Snijders C, Lips P. Effects of the selective estrogen receptor modulator, raloxifene on the somatotropic axis insulin-glucose homeostasis. J Clin Endocrinol Metab. 2001;86:2763-2768.

17. Xing L, Boyce BF. Regulation of apoptosis in osteoclasts and osteoblastic cells. Biochem Biophys Res Commun. 2005;328:709-720.

18. Million Women Study (MWS). Breast cancer and hormone replacement therapy in the Million Women study Collaborators. Lancet. 2003;302:419-427.

19. Writing group for the Women's Health Initiative (WHI) investigators. Risks and benefits of estrogen plus progestin in health postmenopausal: principal results from Women's Health Initiative Randomized Controlled Trial. JAMA. 2002;288:321-333.

20. Anderson GL, Limacher M, Assaf AR, et al. Effects of conjugated equine estrogen in postmenopausal women with hysterectomy: the Women's Health Initiative randomized controlled trial. JAMA. 2004;291:701-712.

21. Siris E, Adachi JD, Lu Y, et al. Effects of raloxifene on fracture severity in postmenopausal women with osteoporosis: results from the MORE study. Multiple outcomes of raloxifene evaluation. Osteoporos Int. 2002;13:907-913.

22. The North American Menopause Society (NAMS). Management of postmenopausal osteoporosis. Position statement. Menopause. 2002;9:84-101. 
23. Riggs BL, Melton LJ. Bone turnover matters: the raloxifene treatment paradox of dramatic decreases in vertebral fractures without commensurate increases in bone density. J Bone Miner Res. 2002;171:11-14.

24. Riggs BL, Hartmann LC. Selective estrogen receptor modulatorsmechanism of actions and application to clinical practice. $N$ Engl $J$ Med. 2003;348:618-629.

25. Fuchs-Young R, Glasebrook AL, Short LL, et al. Raloxifene is a tissueselective agonist/antagonist that functions through the estrogen receptor. Ann N Y Acad Sci. 1995;761:355-360.

26. Brzozowski AM, Pike ACW, Dauter Z, et al. Molecular basis of agonism and antagonism in the oestrogen receptor. Nature. 1997;389:753-758.

27. Anzano MA, Peer CW, Smith JM, et al. Chemoprevention of mammary carcinogenesis in the rat: combined use of raloxifene and 9-cis-retinoic acid. J Natl Cancer Inst. 1996;88:123-125.

28. Taranta A, Brama M, Teti A, et al. The selective estrogen receptor modulator raloxifene regulates osteoclast and osteoblast activity in vitro. Bone. 2002;30:368-376.

29. Cheung J, Mak YT, Papaioannou S, Evans BAJ, Fogelman I, Hampson G. Interleukin-6 (IL-6), IL-1, receptor activator of nuclear factor $\mathrm{KB}$ ligand (RANKL) and osteoprotegerin production by human osteoblastic cells: comparison of the effects of 17-ßoestradiol and raloxifene. $J$ Endocrinol. 2003;177;423-433.

30. Messalli EM, Mainini G, Scaffa C, et al. Raloxifene therapy interacts with serum osteoprotegerin in postmenopausal women. Maturitas. 2007;56:38-44.

31. Simonet WS, Lacey DL, Dunstan CR, et al. Osteoprotegerin: a novel secreted protein involved in the regulation of bone density. Cell. 1997;89:309-319.

32. Lacey DL, Timms E, Tan HL, et al. Osteoprotegerin ligand is a cytokine that regulates osteoclast differentiation and activation. Cell. 1998;93:165-176.

33. Burgess TL, Qian Y, Kaufman S, et al. The ligand for osteoprotegerin (OPGL) directly activates mature osteoclasts. J Cell Biol. 1999;145 527-538.

34. Lacey DL, Tan, HL, Lu J, et al. Osteoprotegerin ligand modulates murine osteoclast survival in vitro and in vivo. Am J Pathol. 2000;157:435-448.

35. Feng, X. RANKing intracellular signaling in osteoclasts. IUBMB Life. 2005;57:389-395.

36. Liao EY, Luo XH, Su X. Comparison of the effects of 17beta-E2 and progesterone on the expression of osteoprotegerin in normal human osteoblast-like cells. J Endocrinol Invest. 2002;25:785-790.

37. Boyle WJ, Simonet WS, Lacey DL. Osteoclast differentiation and activation. Nature. 2003;423:337-342.

38. Hofbauer LC, Schoppet M. Clinical implications of the osteoprotegerin/ RANKL/RANK system for bone and vascular diseases. JAMA. 2004;292:490-495.

39. Viereck V, Gründker C, Blaschke S, et al. Raloxifene concurrently stimulates osteoprotegerin and inhibits interleukin-6 production by human trabecular osteoblasts. J Clin Endocrinol Metab. 2003; 88:4206-4213.

40. Delmas PD, Ensrud KE, Adachi JD, et al. Efficacy of raloxifene on vertebral fracture risk reduction in postmenopausal women with osteoporosis: 4-year results from a randomized clinical trial. $J$ Clin Endocrinol Metab. 2002;87:3609-3617.

41. Byrjalsen I, Leeming DJ, Qvist P, Christiansen C, Karsdal MA. Bone turnover and bone collagen maturation in osteoporosis: effects of antiresorptive therapies. Osteoporos Int. 2008;19:339-348.

42. Johnston CC Jr, Bjarnason NH, Cohen FJ, et al. Long-term effects of raloxifene on bone mineral density, bone turnover, and serum lipid levels in early postmenopausal women: three-year data from 2 double-blind, randomized, placebo-controlled trials. Arch Intern Med. 2000;160:3444-3450.

43. Ettinger B, Black DM, Mitlak BH, et al. Reduction of vertebral fracture risk in postmenopausal women with osteoporosis treated with raloxifene: results from a 3-year randomized clinical trial. Multiple Outcomes of Raloxifene Evaluation (MORE) investigators. JAMA. 1999;282:637-645.
44. Delmas PD, Genant HK, Crans GG, et al. Severity of prevalent vertebral fractures and the risk of subsequent vertebral and nonvertebral fractures: results from the MORE trial. Bone. 2003;33:522-532.

45. Maricic M, Adachi JD, Sarkar S, Wu W, Wong M, Harper KD. Early effects of raloxifene on clinical vertebral fractures at 12 months in postmenopausal women with osteoporosis. Arch Int Med. 2002;162:1140-1143.

46. Qu Y,Wong M, Thiebaud D, Stock JL. The effect of raloxifene therapy on the risk of new clinical vertebral fractures at three and 6 months: a secondary analysis of the MORE trial. Curr Med Res Opin. 2005;21:1955-1959.

47. Siris ES, Harris ST, Eastell R, et al. Skeletal effects of raloxifene after 8 years: results from the Continuing Outcomes Relevant to Evista (CORE) study. J Bone Miner Res. 2005;20:1514-1524.

48. Barrett-Connor E, Mosca L, Collins P, et al.; for the Raloxifene Use for The Heart (RUTH) trial investigators. Effects of raloxifene on cardiovascular events and breast cancer in postmenopausal women. N Engl J Med. 2006;355:125-137.

49. Ensrud KE, Stock JL, Barrett-Connor E, et al. Effects of raloxifene on fracture risk in postmenopausal women: the Raloxifene Use for the Heart Trial. J Bone Miner Res. 2008;23:112-120.

50. Lufkin EG, Sarkar S, Kulkarni PM, et al. Antiresorptive treatment of postmenopausal osteoporosis: review of randomized clinical studies and rationale for the Evista alendronate comparison (EVA) trial. Current Medical Research and Opinion. 2004;20:351-357.

51. Recker D, Kendler C, Recknor T, et al. Comparative effects of raloxifene and alendronate on fracture outcomes in postmenopausal women with low bone mass. Bone. 2007;40:843-851.

52. MacLean C, Newberry S, Maglione M, et al. Systematic review: comparative effectiveness of treatments to prevent fractures in men and women with low bone density or osteoporosis. Ann Intern Med. 2008;148:197-213.

53. Iwamoto J, Sato Y, Uzawa M, Takeda T, Matsumoto H. Comparison of effects of alendronate and raloxifene on lumbar bone mineral density, bone turnover, and lipid metabolism in elderly women with osteoporosis. Yonsei Med J. 2008;49:119-128.

54. Jolly EE, Bjarnason NH, Neven P, et al. Prevention of osteoporosis and uterine effects in postmenopausal women taking raloxifene for 5 years. Menopause. 2003;10:337-344.

55. Neele SJ, Evertz R, De Valk-De Roo G, Roos JC, Netelenbos JC. Effect of 1 year of discontinuation of raloxifene or estrogen therapy on bone mineral density after 5 years of treatment in healthy postmenopausal women. Bone. 2002;30:599-603.

56. Briot K, Tremollieres F, Thomas T, Roux C; pour le comité scientifique du GRIO. How long should patients take medications for postmenopausal osteoporosis? Joint Bone Spine. 2007;74: 24-31.

57. Uusi-Rasi K, Beck TJ, Semanick LM, et al. Structural effects of raloxifene on the proximal femur: results from the multiple outcomes of raloxifene evaluation trial. Osteoporos Int. 2006;17:575-586.

58. Cadarette SM, Katz JN, Brookhart MA, Sturmer T, Stedman MR. Solomon DH. Relative effectiveness of osteoporosis drugs for preventing nonvertebral fracture. Ann Intern Med. 2008;148:637-646.

59. Pelayo I, Haya J, De la Cruz JJ, et al. Raloxifene plus ossein-hydroxyapatite compound versus raloxifene plus calcium carbonate to control bone loss in postmenopausal women: a randomized trial. Menopause. 2008; 15(6):1132-1138

60. Delmas PD, Bjarnason NH, Mitlak BH, et al. Effects of raloxifene on bone mineral density, serum cholesterol concentrations, and uterine endometrium in postmenopausal women. $N$ Engl $J$ Med. 1997;337:1641-1647.

61. Martino S, Cauley JA, Barrett-Connor E, et al. Continuing outcomes relevant to Evista: breast cancer incidence in postmenopausal osteoporotic women in a randomized trial of raloxifene. $J$ Natl Cancer Inst. 2004;96:1751-1761.

62. Martino S, Disch D, Dowsett SA, Keech CA, Mershon JL. Safety assessment of raloxifene over 8 years in a clinical trial setting. Curr Med Res Opin. 2005;21:1441-1452. 
63. Vogel VG, Costantino JP, Wickerham DL, et al. Effects of tamoxifen vs raloxifene on the risk of developing invasive breast cancer and other disease outcomes: the NSABP Study of Tamoxifen and Raloxifene (STAR) P-2 trial. JAMA. 2006;295:2727-2741.

64. Land SR, Wickerham DL, Costantino JP, et al. Patient-reported symptoms and quality of life during treatment with tamoxifen or raloxifene for breast cancer prevention: the NSABP Study of Tamoxifen and Raloxifene (STAR) P-2 trial. J Am Med Assoc. 2006;295:2742-2751.

65. Freedman M, Martin JS, O'Gorman J, et al. Digitized mammography: a clinical trial of postmenopausal women randomly assigned to receive raloxifene, estrogen, or placebo. J Natl Cancer Inst. 2001;93:51-56.

66. Dowsett M, Bundred NJ, Decensi A, et al. Effect of raloxifene on breast cancer cell Ki67 and apoptosis: a double-blind placebo controlled, randomized clinical trial in postmenopausal patients. Cancer Epidemiol Biomarkers Prev. 2001;10:961-966.

67. Cummings SR, Eckert S, Krueger KA, et al. The effect of raloxifene on risk of breast cancer in postmenopausal women: results from the MORE randomized trial. Multiple Outcomes of Raloxifene Evaluation. J Am Med Assoc. 1999;281:2189-2197.

68. Cauley JA, Norton L, Lippman ME, et al. Continued breast cancer risk reduction in postmenopausal women treated with raloxifene: 4-year results from the MORE trial. Breast Cancer Res Treat. 2001;65:125-134.

69. Burshell AL, Song J, Dowsett SA, et al. Relationship between bone mass, invasive breast cancer incidence and raloxifene therapy in postmenopausal women with low bone mass or osteoporosis. Curr Med Res Opin. 2008;24:807-813.

70. Grady D, Cauley JA, Geiger MJ, et al; Raloxifene Use for The Heart Trial Investigators. Reduced incidence of invasive breast cancer with raloxifene among women at increased coronary risk. $J$ Natl Cancer Inst. 2008;100:854-861.

71. Barrett-Connor E, Grady D, Sashegyi A, et al. Raloxifene and cardiovascular events in osteoporotic postmenopausal women: four-year results from the MORE (Multiple Outcomes of Raloxifene Evaluation) randomized trial. JAMA. 2002;287:847-857.

72. Walsh BW, Kuller LH, Wild RA, et al. Effects of raloxifene on serum lipids and coagulation factors in healthy postmenopausal women. JAMA. 1998;279:1445-1451.

73. Walsh BW, Paul S, Wild RA, et al. The effects of hormone replacement therapy and raloxifene on C-reactive protein and homocysteine in healthy postmenopausal women: a randomized, controlled trial. J Clin Endocrinol Metab. 2000;85:214-218.

74. Dayspring T, Qu Y, Keech C. Effects of raloxifene on lipid and lipoprotein levels in postmenopausal osteoporotic women with and without hypertriglyceridemia. Metabolism. 2006;55:972-979.

75. Nanetti L, Camilletti A, Francucci CM, et al. Role of raloxifene on platelet metabolism and plasma lipids. Eur J Clin Invest. 2008;38:117-125.

76. Stampfer MJ, Colditz GA. Estrogen replacement therapy and coronary heart disease: a quantitative assessment of the epidemiologic evidence. Prev Med. 1991;20:47-63.

77. Grady D, Rubin SM, Petitti DB, et al. Hormone therapy to prevent disease and prolong life in postmenopausal women. Ann Intern Med. 1992;117:1016-1037.

78. Colacurci N, Fornaro F, Cobellis L, et al. Raloxifene slows down the progression of intima-media thickness in postmenopausal women. Menopause. 2007;14:879-884.

79. Grady D, Ettinger B, Moscarelli E, et al. Safety and adverse effects associated with raloxifene: Multiple Outcomes of Raloxifene Evaluation. Obstet Gynecol. 2004;104:837-844.

80. Hulley S, Grady D, Bush T, et al. Randomized trial of estrogen plus progestin for secondary prevention of coronary heart disease in postmenopausal women. Heart and Estrogen/progestin Replacement Study (HERS) Research Group. JAMA. 1998;280:605-613.

81. Adomaityte J, Farooq M, Qayyum R. Effect of raloxifene therapy on venous thromboembolism in postmenopausal women. A meta-analysis. Thromb Haemost. 2008;99:338-342.
82. Blumenthal RS, Baranowski B, Dowsett SA. Cardiovascular effects of raloxifene: the arterial and venous systems. Am Heart $J$. 2004; 147:783-789.

83. Ishani A, Blackwell T, Jamal SA, Cummings SR, Ensrud KE; MORE Investigators. The effect of raloxifene treatment in postmenopausal women with CKD. Am Soc Nephrol. 2008;19:1430-1438.

84. Komi J, Lankinen KS, DeGregorio M, et al. Effects of ospemifene and raloxifene on biochemical markers of bone turnover in postmenopausal women. J Bone Miner Metab. 2006;24:314-318.

85. Stump AL, Kelley KW, Wensel TM. Bazedoxifene: a third-generation selective estrogen receptor modulator for treatment of postmenopausal osteoporosis. Ann Pharmacother. 2007;41:833-839.

86. Gennari L. Lasofoxifene: a new type of selective estrogen receptor modulator for the treatment of osteoporosis. Drugs Today. 2006;42: $355-367$.

87. Lee A, Radecki D, Wolter K, et al. Lasofoxifene phase 2 and phase 3 clinical trial design and strategy [abstract]. J Bone Miner Res. 2005;20: S1 M384

88. Gennari L, Merlotti D, Valleggi F, Martini G, Nuti R. Selective estrogen receptor modulators for postmenopausal osteoporosis: current state of development. Drugs Aging. 2007;24:361-379.

89. Vogelvang TE, van der Mooren MJ, Mijatovic V, Kenemans P. Emerging selective estrogen receptor modulators: special focus on effects on coronary heart disease in postmenopausal women. Drugs. 2006;66:191-221.

90. Miller PD, Chines AA, Christiansen C, et al. Effects of bazedoxifene on BMD and bone turnover in postmenopausal women: 2-yr results of a randomized, double-blind, placebo-, and active-controlled study. J Bone Miner Res. 2008;23:525-535.

91. Carranza-Lira S, Gooch AL, Saldivar N, Osterwalder MS. Climacteric symptom control after the addition of low-dose esterified conjugated estrogens to raloxifene standard doses. Int J Fertil Womens Med. 2007;52:93-96.

92. Pinkerton JV, Dalkin AC. Combination therapy for treatment of osteoporosis: a review. Am J Obstet Gynecol. 2007;197:559-565.

93. Papaioannou A, Kennedy CC, Dolovich L, Lau E, Adachi JD. Patient adherence to osteoporosis medications: problems, consequences and management strategies. Drugs Aging. 2007;24:37-55.

94. Pasion EG, Sivananthan SK, Kung AW, et al. Comparison of raloxifene and bisphosphonates based on adherence and treatment satisfaction in postmenopausal Asian women. $J$ Bone Miner Metab. 2007;25: 105-113.

95. Michalska D, Stepan JJ, Basson BR, Pavo I. The effect of raloxifene after discontinuation of long-term alendronate treatment of postmenopausal osteoporosis. J Clin Endocrinol Metab. 2006;91:870-877.

96. Rosa J, Vanuga P, Payer J, Svobodník A. Raloxifene in clinical practice. Results of the non-interventional study CORAL (COmpliance with RALoxifene). Vnitr Lek. 2008;54:217-9, 221-4.

97. Lippuner K. Medical treatment of vertebral osteoporosis. Eur Spine J. 2003;12 Suppl 2:S132-S141.

98. Barrett-Connor E, Cauley JA, Kulkarni PM, Sashegyi A, Cox DA, Geiger MJ. Risk-benefit profile for raloxifene: 4-year data from the Multiple Outcomes of Raloxifene Evaluation (MORE) randomized trial. J Bone Miner Res. 2004;19:1270-1275.

99. US Food and Drug Administration. EVISTA label. NDA no. 022042 approved on 09/13/2007.

100. Lee W-L, Chaob H-T, Cheng M-H, Wang P-H. Rationale for using raloxifene to prevent both osteoporosis and breast cancer in postmenopausal women. Maturitas. 2008;60:92-107.

101. Kanis JA, Burlet N, Cooper C, et al. on behalf of the European Society for Clinical and Economic Aspects of Osteoporosis and Osteoarthritis (ESCEO). European guidance for the diagnosis and management of osteoporosis in postmenopausal women. Osteoporos Int. 2008;19: 399-428.

102. Jordan VC. SERMs: meeting the promise of multifunctional medicines. J Natl Cancer Inst. 2007;99:350-356. 